Tersedia online di: http://ejournal-balitbang.kkp.go.id/index.php/bawal
e-mail:bawal.puslitbangkan@gmail.com
BAWAL wIDYA RISET PERIKANAN TANGKAP
Volume 10 Nomor 2 Agustus 2018
p-ISSN: 1907-8226
e-ISSN: 2502-6410
BAWAL
Nomor Akreditasi Kementerian RISTEKDIKTI: 21/E/KPT/2018

\title{
PARAMETER POPULASI UDANG DOGOL (Metapenaeus ensis De Haan, 1984) DI SELAT BANGKA, SUMATERA SELATAN
}

\section{POPULATION PARAMETERS OF GREASYBACK SHRIMP (Metapenaeus ensis De Haan, 1984) IN BANGKA STRAIT, SOUTH SUMATERA}

\author{
${\text { Pratiwi Lestari*1, }{ }^{*} \text { Tirtadanu }^{1} \text {, Duranta D. Kembaren }}^{1}$ dan Wedjatmiko $^{2}$ \\ ${ }^{1}$ Peneliti pada Balai Riset Perikanan Laut - Jl. Raya Bogor KM 47, Nanggewer- Cibinong, Bogor \\ ${ }^{2}$ Peneliti pada Pusat Riset Perikanan - Jl. Pasir Putih II, Gd II, BRSDM KP Ancol Timur, Jakarta Utara \\ Teregistrasi I tanggal: 24 Agustus 2017; Diterima setelah perbaikan tanggal: 03 Agustus 2018; \\ Disetujui terbit tanggal: 27 Agustus 2018
}

\begin{abstract}
ABSTRAK
Parameter populasi udang dogol (Metapenaeus ensis) di Selat Bangka merupakan informasi penting sebagai bahan masukan dalam opsi kebijakan pengelolaan perikanan udang yang berkelanjutan. Penelitian ini bertujuan untuk mengkaji parameter populasi dan tingkat pemanfaatan udang dogol di perairan Selat Bangka berdasarkan pada data biologi (struktur ukuran, jenis kelamin dan tingkat kematangan gonad). Pengumpulan data biologi dilakukan selama bulan Februari - November 2014 di Pusat Pendaratan Ikan Banyuasin. Pendugaan parameter populasi dilakukan dengan bantuan program FiSAT II, hasil penelitian menunjukkan rata-rata udang dogol yang tertangkap belum melakukan pemijahan $\left(\mathrm{L}_{\mathrm{c}}<\mathrm{L}_{\mathrm{m}}\right)$. Puncak pemijahan udang diduga terjadi pada bulan Juli. Panjang karapas asimtotik (CL,) udang dogol jantan sebesar 45,0 $\mathrm{mm}$ dan betina sebesar 49,5 $\mathrm{mm}$. Laju pertumbuhan (K) udang dogol jantan sebesar 1,40 per tahun dan betina sebesar 1,45 per tahun. Laju mortalitas total (Z) udang dogol jantan sebesar 4,56 per tahun, laju kematian alamiahnya (M) sebesar 2,02 per tahun dan laju kematian karena penangkapan (F) sebesar 2,54 per tahun. Laju mortalitas total (Z) udang dogol betina sebesar 3,98 per tahun, laju kematian alamiahnya (M) sebesar 2,01 per tahun dan laju kematian karena penangkapan (F) sebesar 1,97 per tahun. Laju eksploitasi udang dogol (E) di Selat Bangka yaitu 0,56 pada jantan dan 0,49 pada betina. Hal tersebut menunjukkan udang dogol jantan di Selat Bangka telah dimanfaatkan secara penuh (fully exploited) dan perlu kewaspadaan dalam pemanfaatannya. Pengaturan mata jaring, jumlah armada dan pengaturan musim penangkapan perlu dilakukan agar pemanfaatan perikanan udang dapat berkelanjutan.
\end{abstract}

Kata Kunci: Udang Dogol; Parameter Populasi; Selat Bangka

\section{ABSTRACT}

The estimation of the parameter population of greasyback shrimp (Metapenaeus ensis) in Bangka Strait was an important information as a fisheries management policy for sustainable shrimp fisheries. The aims of this research was to assess population parameters and exploitation rate of greasyback shrimp in Bangka Strait based on biological data (size distribution, sex ratio and gonad maturity). Biological data collected from February - November 2014 at landing base in Banyuasin. The Method to estimate population dynamic was analyzed by using FiSAT II, the results showed that the average of greasyback shrimp that was captured had not spawned yet $\left(L_{c}<L_{m}\right)$. The spawning season occurred in July. Carapace asymptotic length $\left(C L_{\text {, }}\right)$ of male shrimp was 45,0 mm and the female was 49,5 $\mathrm{mm}$. The growth parameter of greasyback shrimp was 1,40/year for male and 1,45/year for female. Total mortality rate $(Z)$, natural mortality rate $(M)$ and fishing mortality rate $(F)$ for male shrimp were 4,82/year, 2,06/year and 2,76/year. Total mortality rate (Z), natural mortality rate (M) and fishing mortality rate $(F)$ for female shrimp were 3,98/year, 2,01/year and 1,97/year. Exploitation rate of greasyback shrimp in Bangka Strait were 0,57 for male and 0,49 for female. The exploitation of male greasyback shrimp was fully exploited so that it needed careful regulation. Therefore, the regulation about mesh size, amount of fishing fleet, periodicity of fishing were needed for sustainable shrimp fisheries.

Keywords: Greasyback shrimp; Population Parameters; Bangka Strait 


\section{PENDAHULUAN}

Perairan Selat Bangka merupakan salah satu perairan yang potensial bagi perikanan laut. Total produksi perikanan tangkap di Selat Bangka khususnya di Provinsi Sumatera Selatan pada tahun 2016 sebesar 69.583 ton (DJPT, 2017). Udang dogol merupakan salah satu udang Penaeid yang memiliki nilai ekonomi penting. Nilai produksi udang di provinsi Sumatera Selatan pada tahun 2016 sebesar 5.743 ton (DJPT, 2017). Penangkapan udang dogol di Selat Bangka menggunakan kapal berukuran 3 GT yang terbuat dari bahan kayu dan menggunakan alat tangkap jaring kantong (trammel net). Jaring terdiri dari tiga lapis, yaitu dua lapis dibagian luar dengan ukuran mata jaring 4 (empat) inchi dan satu lapis jaring di bagian dalam (tengah) dengan ukuran mata jaring 1 (satu) inchi.

Aktivitas penangkapan udang di Selat Bangka telah menjadi penyokong utama untuk memenuhi kebutuhan ekonomi nelayan jaring kantong di Kabupaten Banyuasin. Penangkapan udang dilokasi ini dilakukan sangat intensif, sehingga aktivitas penangkapan tersebut perlu dikelola agar pemanfaatan sumberdaya udang dapat berkelanjutan. Oleh sebab itu, informasi dinamika populasi dan tingkat pemanfaatan diperlukan sebagai dasar dalam pengelolaan perikanan laut.

Penelitian tentang parameter populasi udang dogol telah dilakukan pada beberapa perairan di Indonesia diantaranya ukuran pertama kali matang kelamin, musim pemijahan, dan parameter pertumbuhan udang dogol (Metapenaeus ensis de haan) di Perairan Cilacap dan sekitarnya (Suman \& Boer, 2005). Informasi dinamika populasi udang dogol (Metapenaeus ensis) di Selat Bangka tergolong masih minim. Penelitian ini bertujuan untuk mengetahui parameter populasi dan tingkat pemanfaatan udang dogol di perairan Selat Bangka sebagai informasi dasar dalam pengelolaan perikanan udang yang berkelanjutan.

\section{METODEPENELITIAN}

Pengambilan sampel udang dogol (Metapenaeus ensis) dilakukan selama bulan Februari 2014 sampai November 2014. Pengambilan sampel yang dibedakan menurut jenis kelaminnya dilakukan di lokasi pendaratan di daerah Sungsang, Kabupaten Banyuasin, Sumatera Selatan (Gambar 1).

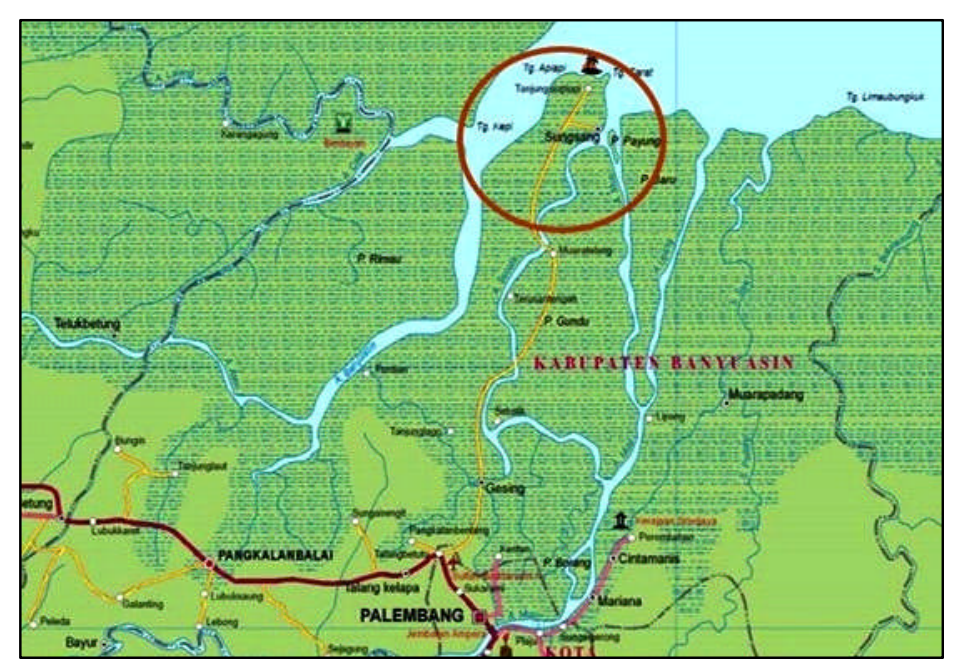

Gambar 1. Lokasi pengambilan sampel udang di Selat Bangka, Sumatera Selatan, 2014.

Figure 1. Sampling location of shrimp in Bangka Strait, South Sumatera, 2014.

Sampel udang dogol yang diperoleh sebanyak 1783 ekor terdiri dari 524 udang jantan dan 1259 udang betina. Penyebaran bulanan ukuran udang jantan dan betina dikemukakan pada lampiran tabel 1 dan 2 diperoleh dari hasil tangkapan nelayan jaring kantong (trammel net) yang melakukan penangkapan di Selat Bangka. Data yang dikumpulkan meliputi panjang karapas, jenis kelamin dan tingkat kematangan gonad, kemudian di analisis untuk mengetahui rasio tingkat kematangan gonad, panjang karapas rata-rata tertangkap (Lc), panjang karapas pertama kali matang gonad (Lm), laju pertumbuhan, laju kematian dan eksploitasi udang dogol di Selat Bangka.
Kematangan gonad udang betina diamati secara visual berdasarkan karakteristik pada bagian punggungnya dan diklasifikasikan berdasarkan Motoh (1981). Panjang pertama kali matang gonad (Lm) diperoleh dengan memasukkan nilai panjang karapas dan $\mathrm{P}_{\mathrm{Lm}}$ ke dalam bentuk grafik fungsi logistik (King, 1995). Persamaan yang digunakan sebagai berikut :

$$
P_{C L m}=\frac{1}{1+\exp (a C l+b)}
$$

Panjang karapas udang pertama kali tertangkap (Lc) diperoleh melalui pendekatan fungsi logistik dengan persamaan (Sparre \&Venema, 1992) : 


$$
S_{C L}=\frac{1}{1+\exp \left(a-b^{*} C L\right)}
$$

Di mana: $S_{C L}$ adalah selektivitas alat tangkap trammel $n e t$, a dan b adalah konstanta, CL adalah panjang karapas udang dan nilai Lc diperoleh dari a/b.

Parameter pertumbuhan Von Bertalanffy diperoleh berdasarkan analisis pergeseran modus dari ukuran panjang karapas setiap bulan selama 1 tahun dengan rentang ukuran panjang $16-50 \mathrm{~mm}$ dan kelas panjang $2 \mathrm{mmCL}$. Panjang karapas asimptotik $\left(\mathrm{CL}_{\infty}\right)$ dan koefisien pertumbuhan $(\mathrm{K})$ diduga dengan program ELEFAN dalam programFiSAT II (Gayanilo et al., 2005). Nilai t (umur pada saat 0 tahun) diduga berdasarkan persamaan Pauly (1983) yaitu :

$\log \left(-\mathrm{t}_{0}\right)=(-0,3922)-0,2752 \log \mathrm{CL}_{\infty}-1,038 \log \mathrm{K}$

Nilai Mortalitas alami (M) diduga dengan persamaan Pauly, menggunakan nilai temperatur rata-rata perairan (Pauly et al., 1984) : $\log M=(-0,0066)-0,279 \log C_{\infty}+0,6543 \log K+0,4634$

$\log \mathrm{T}$

Nilai Mortalitas total (Z) diduga dengan metode kurva konversi hasil tangkapan dengan panjang (length converted catch curve) pada paket program FiSAT II (Pauly, 1983; Gayanilo et al., 2005). Mortalitas penangkapan dan laju eksploitasi diduga dengan persamaan: $\mathrm{F}=\mathrm{Z}-\mathrm{M}$ dan $\mathrm{E}=\mathrm{F} / \mathrm{Z}$.

\section{HASIL DAN BAHASAN \\ Hasil}

\section{Rata-rata Ukuran Panjang karapas Pertama kali tertangkap (Lc)}

Panjang karapas udang dogol pertama kali tertangkap (Lc) diperoleh dengan memasukkan nilai panjang karapas dalam bentuk grafik fungsi logistik. Berdasarkan analisis tersebut, diperoleh panjang udang dogol pertama kali tertangkap (Lc 50\%) jaring trammel adalah 30,68 mm (Gambar 2).

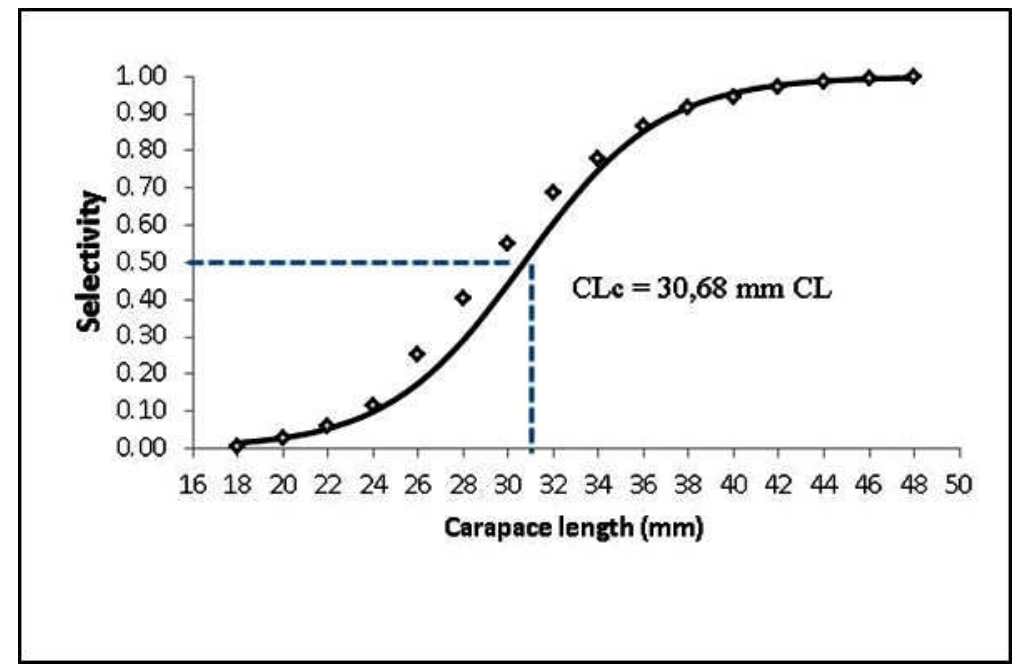

Gambar 2. Panjang karapas pertama kali tertangkap (Lc) Metapenaeus ensis di Selat Bangka, 2014.

Figure 2. Carapace length at first captured (Lc) of Metapenaeus ensis in Bangka Strait, 2014.

\section{Rata-Rata Ukuran Panjang Karapas Pertama kali Matang Gonad (Lm)}

Panjang karapas rata-rata udang dogol matang gonad (Lm) diperoleh dengan memasukkan panjang karapas dan proporsi matang gonad dalam grafik fungsi logistik. Berdasarkan hasil analisis diperoleh ukuran rata-rata panjang karapas udang dogol betina matang gonad (Lm) sebesar 33,23 mm (Gambar 3).

\section{Musim Pemijahan}

Musim pemijahan udang dogol diperoleh melalui hasil pengamatan visual terhadap kematangan gonad. Tingkat kematangan gonad udang dogol pada bulan Februari hingga Juni menunjukkan belum matang (TKG 1 dan TKG 2) lebih dominan dibandingkan udang dogol matang gonad (TKG 3 dan TKG4). Udang dogol matang gonad lebih dominan pada bulan Juli dengan proporsi sebesar 74\% (Gambar 4). 


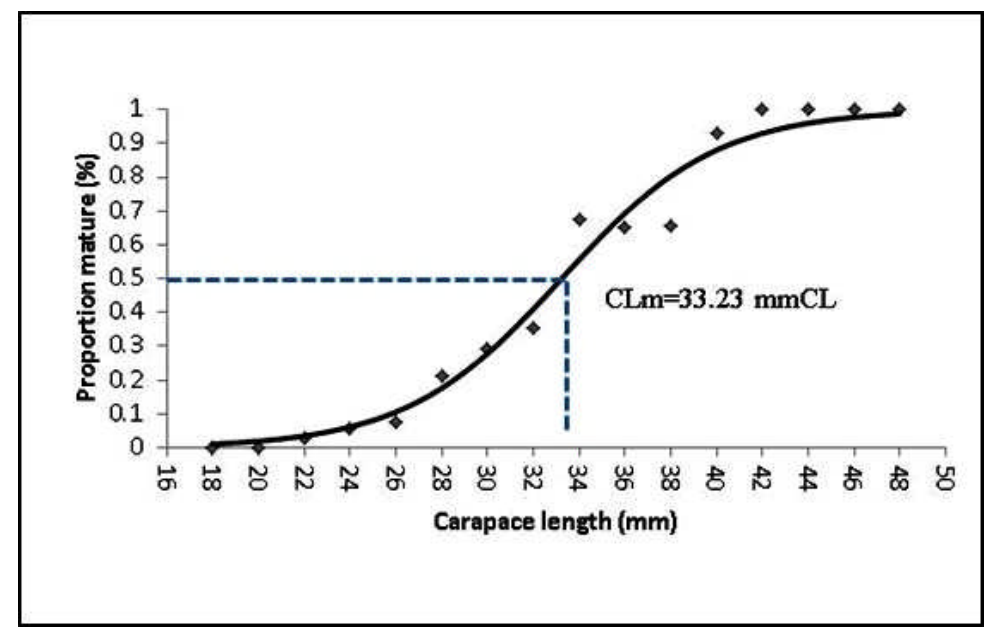

Gambar 3. Grafik panjang karapas pertama kali matang gonad (Lm) Metapenaeus ensis di Perairan Selat Bangka, 2014. Figure 3. Carapace length at first mature ( $\mathrm{Lm}$ ) of Metapenaeus ensis in Bangka Strait, 2014.

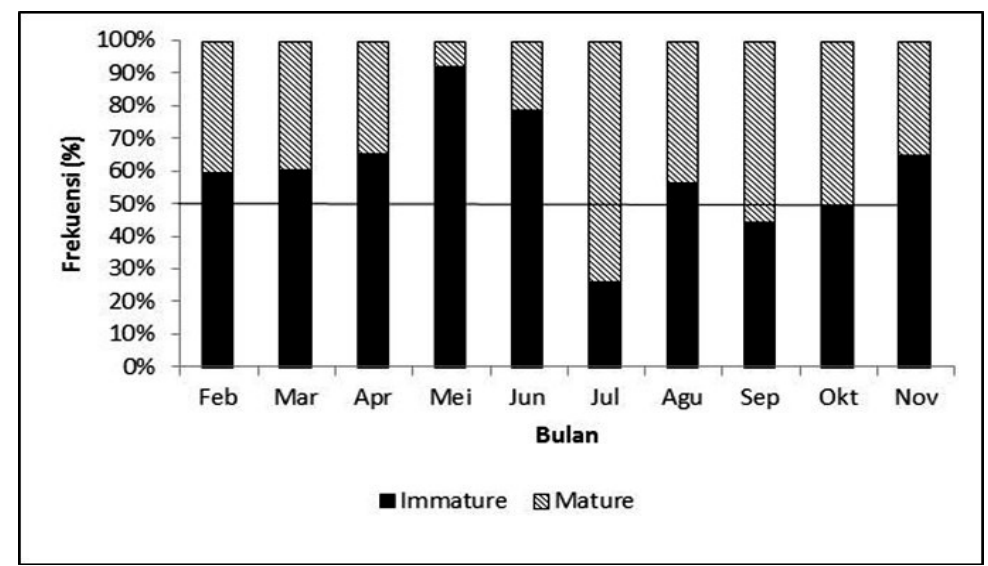

Gambar 4. Tingkat Kematangan Gonad (TKG) udang dogol betina di Selat Bangka, 2014. TKG I dan II = belum matang, TKG III dan IV=matang.

Figure 4. Gonadal maturity stage of greasyback shrimp in Bangka Strait, 2014. Stage I and II = Immature, Stage III and IV = Mature.

\section{Laju Pertumbuhan}

Laju pertumbuhan diperoleh berdasarkan persamaan Von Bertalanffy dengan melihat pergesaran modus ukuran panjang karapas udang selama 1 tahun setiap bulannya.
Panjang karapas asimtotik udang dogol jantan sebesar 45,0 mm sedangkan udang dogol betina sebesar 49,5 mm. Penyebaran frekuensi panjang karapas udang dogol yang dirunut dengan program ELEFAN disajikan pada Gambar 5 dan 6.

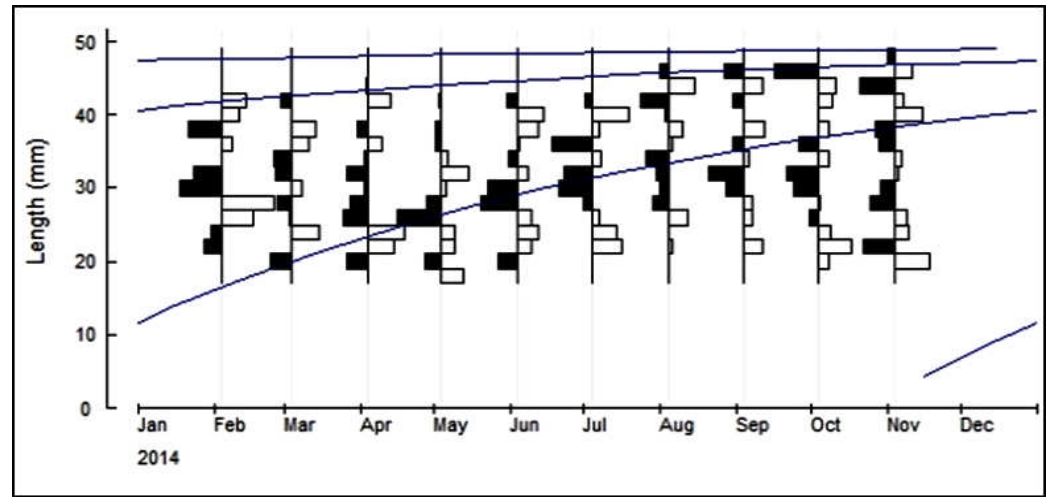

Gambar 5. Penyebaran frekuensi panjang karapas udang dogol (Metapenaeus ensis de Haan) jantan yang dirunut dengan ELEFAN.

Figure 5. Carapace length frequency distribution of greasyback shrimp (Metapenaeus ensis de Haan) male by using ELEFAN method. 


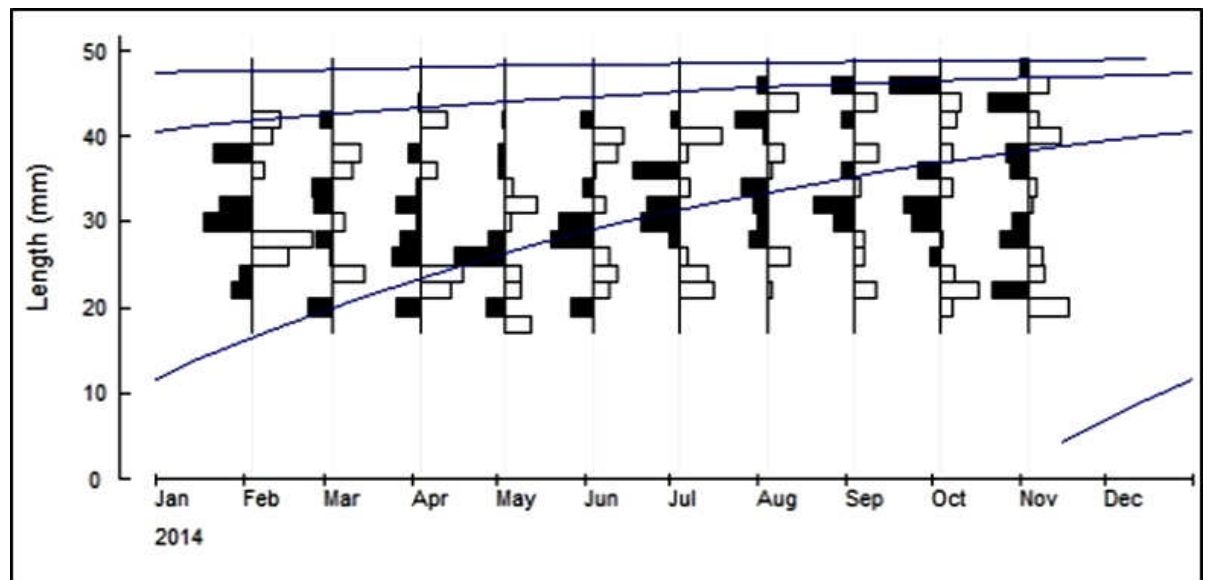

Gambar 6. Penyebaran frekuensi panjang karapas udang dogol (Metapenaeus ensis de Haan) betina yang dirunut dengan ELEFAN.

Figure 6. Carapace length frequency distribution of greasyback shrimp (Metapenaeus ensis de Haan) female by using ELEFAN method.

Berdasarkan rumus pertumbuhan Von Bertalanffy, persamaan $\mathrm{L}_{\mathrm{t}}=49.5\left(1-\mathrm{e}^{-1.45(\mathrm{t}+0.2036)}\right)$ Kurva kurva pertumbuhan udang dogol jantan di Selat Bangka pertumbuhan menunjukkan udang dogol jantan dan betina mengikuti persamaan $\mathrm{L}_{\mathrm{t}}=45.0\left(1-\mathrm{e}^{-}\right.$mencapai panjang karapas asimptotik pada umur 24 bulan 1.40(t+0.2.16) $)$ sedangkan udang dogol betina mengikuti Gambar (7 dan 8).

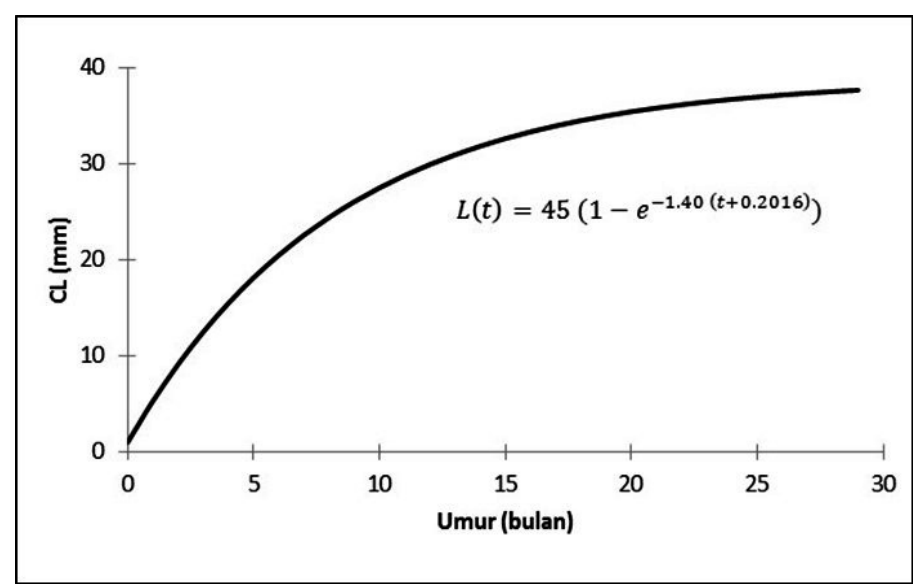

Gambar 7. Kurva pertumbuhan udang dogol jantan di perairan Selat Bangka, 2014

Figure 7. The curve of growth pattern of male greasyback shrimp in Bangka Strait, 2014.

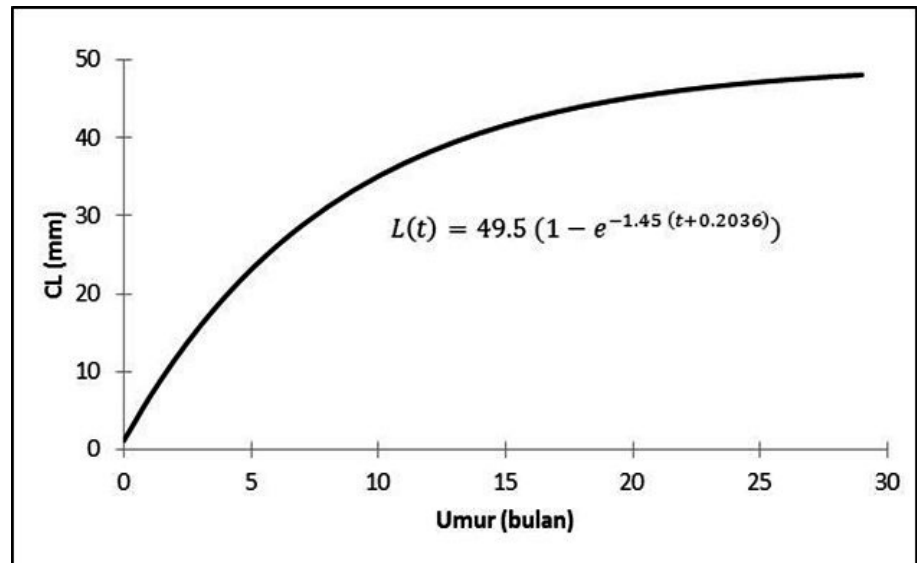

Gambar 8. Kurva pertumbuhan udang dogol betina di perairan Selat Bangka, 2014.

Figure 8. The curve of growth pattern of female greasyback shrimp in Bangka Strait, 2014. 


\section{Laju Kematian dan Eksploitasi}

Dugaan nilai mortalitas alami menggunakan persamaan Pauly 1984 dengan nilai temperature rata-rata perairan $29^{\circ} \mathrm{C}$. Dugaan laju mortalitas total (Z), mortalitas alami (M) dan mortalitas akibat penangkapan udang dogol jantan sebesar

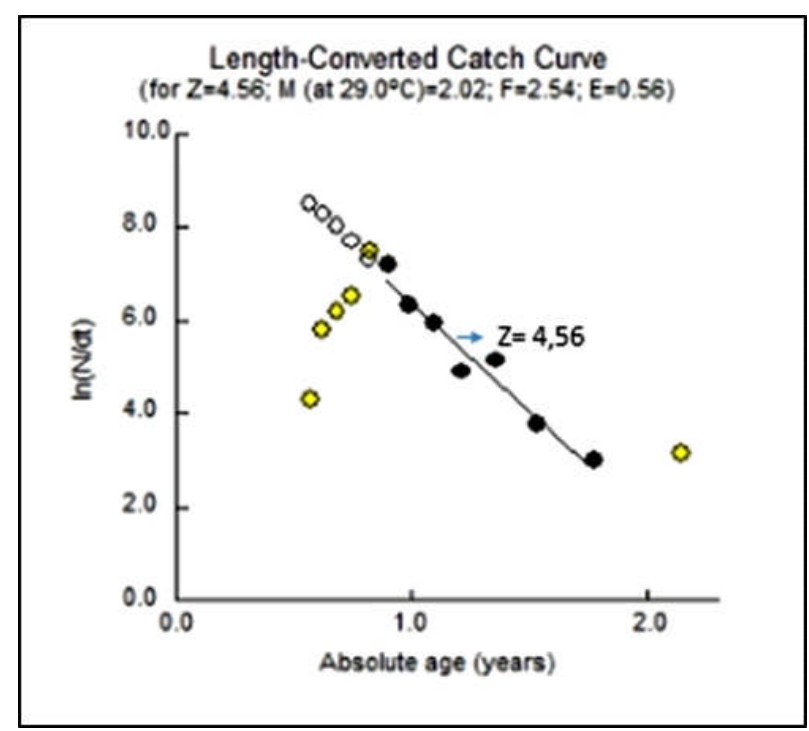

Gambar 9. Kurva konversi panjang karapas udang dogol jantan di perairan Selat Bangka, 2014.

Figure 9. The length converted catch curve of greasyback shrimp male in Bangka Strait, 2014.

\section{BAHASAN}

Panjang karapas rata-rata tertangkap udang dogol di Selat Bangka lebih kecil dibandingkan nilai pertama kali matang gonad ( $\mathrm{Lc}=30.67 ; \mathrm{Lm}=33,23)$. Hal tersebut menunjukkan bahwa sebagian besar udang dogol yang tertangkap diduga belum melakukan pemijahan (individu muda) sehingga perlu dilakukan pengaturan ukuran mata jaring agar tertangkapnya udang dogol yang belum memijah dapat diminimalkan. Rata-rata ukuran pertama kali matang gonad udang dogol di perairan Cilacap dan sekitarnya lebih kecil yaitu pada panjang karapas $31,8 \mathrm{~mm}$ (Suman \& Boer, 2005). Perbedaan nilai Lm pada berbagai perairan dipengaruhi beberapa faktor diantaranya ketersediaan makanan dan kondisi lingkungan lainnya, seperti suhu dan salinitas. Menurut Udupa (1986), ukuran pada saat kematangan gonad bervariasi antara spesies dan di dalam spesies yang sama.

Berdasarkan perbandingan rasio kematangan gonad tiap bulan, udang dogol betina matang gonad pada bulan juli cukup tinggi dibandingkan dengan bulan lainnya, yaitu dengan proporsi sebesar $74 \%$, musim pemijahan udang dogol terjadi sepanjang tahun dan puncaknya diduga terjadi pada bulan Juli-Agustus (musim timur). Hasil ini yang tidak jauh berbeda dengan musim penangkapan udang dogol di perairan Cilacap yang terjadi pada musim
4,56 per tahun, 2,02 per tahun dan 2,54 per tahun (Gambar 9) ; sedangkan pada betina sebesar 3,98 per tahun, 2,01 per tahun dan 1,97 per tahun (Gambar 10). Dengan demikian diduga Laju eksploitasi udang dogol jantan (E/ $\mathrm{Z}=0,56)$ lebih besar dibandingkan udang dogol betina $(\mathrm{E}$ $=0,49)$.

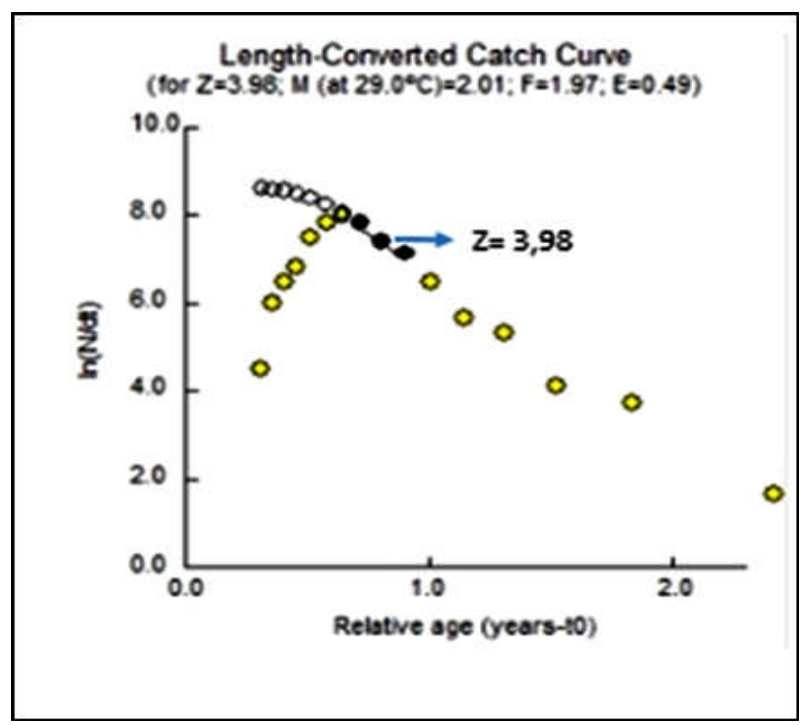

Gambar 10. Kurva konversi panjang karapas udang dogol betina di perairan Selat Bangka, 2014.

Figure 10. The length converted catch curve of greasyback shrimp female in Bangka Strait, 2014.

timur di bulan Agustus-September ditunjukkan oleh nilai IMP sebesar 100\% (Miftahudin et al., 2016). Hasil tersebut dapat digunakan sebagai dasar kebijakan berkaitan dengan pembatasan aktivitas penangkapan pada saat musim pemijahan (close season).

Panjang karapas infinitf udang dogol betina lebih besar dibandingkan jantan yaitu sebesar 49,5 $\mathrm{mm}$ pada betina dan 45,0 mm pada jantan. Hasil serupa ditemukan pada udang dogol di Perairan Kalimantan (Hasanah et al., 2017) dan udang dogol di perairan Cilacap (Suman \& Boer, 2005).

Koefisien pertumbuhan (K) udang dogol (M.ensis) sebesar 1,45 per tahun. Koefisien pertumbuhan udang dogol lebih besar dari satu menunjukkan udang dogol memiliki pertumbuhan yang cepat (Gulland, 1983; Naamin, 1984). Koefisien pertumbuhan udang dogol di Selat Bangka sebesar 1,45 per tahun tidak jauh berbeda dengan udang dogol Metapenaeus ensis di Perairan Arafura sebesar 1,33 per tahun (Suman et al., 2017).

Laju mortalitas total (Z), mortalitas alami (M) dan mortalitas akibat penangkapan udang dogol jantan sebesar 4,82 per tahun, 2,06 per tahun dan 2,76 per tahun sedangkan pada betina sebesar 3,98 per tahun, 2,01 per tahun dan 1,97 per tahun. Laju kematian populasi di suatu lingkungan perairan dipengaruhi oleh berbagai faktor diantaranya 
penurunan kualitas perairan, kekurangan makanan, kompetisi dan predasi (King, 1995; Niamaimandi et al., 2007). Laju kematian alami udang dogol di perairan Selat Bangka tidak jauh berbeda dengan mortalitas alami udang putih di perairan Kotabaru, Kalimantan Selatan (Suman \& Umar, 2010). Laju mortalitas alami udang dogol tergolong tinggi di mana menurut Beverton \& Holt (1959), spesies dengan pertumbuhan yang cepat memiliki nilai $\mathrm{k}$ dan laju mortalitas alami yang tinggi.

Laju eksploitasi udang dogol di Selat Bangka yaitu 0,57 pada jantan dan 0,49 pada betina. Laju eksploitasi udang dogol jantan di daerah penelitian lebih besar dibandingkan laju ekploitasi udang windu di perairan Tarakan dan udang putih di perairan Kotabaru dengan nilai E sebesar 0,56 per tahun (Kembaren \& Nurdin, 2013; Suman \& Umar, 2010). Gulland (1983) menyatakan titik optimum laju eksploitasi sebesar 0,5. Berdasarkan hal tersebut, laju eksploitasi udang dogol betina masih dalam kondisi optimum penangkapan, namun laju eksploitasi udang dogol jantan telah melebihi kondisi optimum atau dalam keadaan jenuh (fully exploited) dan mendekati lebih tangkap (overfishing) sehingga diperlukan kewaspadaan dalam mengalokasikan aktivitas penangkapan.

Rekomendasi yang dapat disimpulkan sebagai dasar pengelolaan penangkapan yaitu pembatasan aktivitas penangkapan berdasarkan kuota jumlah armada penangkapan dan waktu penangkapan serta pengaturan ukuran mata jaring. Aktivitas penangkapan perlu dibatasi berkaitan dengan keadaan laju eksploitasi yang telah melebihi kondisi optimum pada udang dogol jantan di Selat Bangka dengan nilai laju eksploitasi $>0,5$. Aktivitas penangkapan sebaiknya dibatasi pada saat musim pemijahan yaitu pada bulan Juli.

\section{KESIMPULAN}

Rata-rata udang dogol (Metapenaeus ensis) yang tertangkap di perairan Selat Bangka diduga belum melakukan pemijahan. Nilai rata-rata ukuran pertama kali tertangkap lebih kecil dari rata-rata ukuran pertama kali matang gonad $\left(\mathrm{L}_{\mathrm{c}}<\mathrm{L}_{\mathrm{m}}\right)$. Puncak pemijahan diduga terjadi pada bulan Juli ditunjukkan oleh udang dogol dengan proporsi TKG IV sebesar 78\%. Laju eksploitasi udang dogol (E) di Selat Bangka yaitu 0,57 pada udang jantan dan mendekati lebih tangkap (overfishing) sehingga perlu kewaspadaan dalam pemanfaatannya, sedangkan laju eksploitasi pada udang betina sebesar 0,49. Berdasarkan informasi tersebut, pemanfaatan udang dogol sebaiknya tidak dilakukan penambahan armada penangkapan karena status pemanfaatannya mengarah kepada lebih tangkap (overfishing).

\section{PERSANTUNAN}

Tulisan ini merupakan bagian dari kegiatan "Penelitian Stok dan Optimasi Pemanfaatan Sumberdaya Udang Penaeid dan Krustasea Lain dalam Mendukung Industrialisasi Perikanan di Selat Malaka (WPP 571) dan Laut Cina Selatan (WPP 711)" yang diselenggarakan oleh Balai Riset Perikanan Laut, Cibinong, Bogor.

\section{DAFTAR PUSTAKA}

Beverton, R.J.H. \& Holt, S.J. (1959). A review of the life spans and mortality rates of fish in nature and their relation to growth and other physiological characteristics. Ciba Foundation Colloqia on Ageing, 5, 142-180.

DJPT (Direktorat Jenderal Perikanan Tangkap). (2017). Statistik perikanan tangkap Indonesia menurut provinsi 2017. Direktorat Jenderal Perikanan Tangkap. $325 \mathrm{p}$.

Gayanilo, F.C. Jr., Sparre, P. \& Pauly, D. (2005). FAOICLARM Stock Assessment Tools II (FISAT II). Revised version. User's guide. FAO Computerized Information Series (Fisheries) No. 8. Revised Version. FAO Rome.

Gulland, J.A. (1983). Fish Stock Assessment: a manual of basic methods. John Wiley and Sons. Chicester. 233 pp.

Hasanah, A., Ernawati, T. \& Suman, A. (2017). Beberapa aspek biologi udang dogol (Metapenaeus ensis) di perairan Tanah Laut, Kalimantan Selatan. Prosiding Simposium Nasional Krustase. 15-22.

Kembaren, D.D. \& Nurdin, E. (2013). Dinamika populasi dan tingkat pemanfaatan udang windu (Penaeus monodon) di perairan Tarakan, Kalimantan Timur. $J$. Lit. Perikan. Ind. Vol.19 (4), 221-226. doi: 10.15578/ jppi.19.4.2013.221-226

King, M. (1995). Fishery Biology, Assessment and Management. United Kingdom: Fishing New Books. $341 \mathrm{p}$.

Miftahudin., Mawardi, W. \& Riyanto, M. 2016. Tingkat Pemanfaatan dan Pola Musim Udang Dogol (Metapenaeus Ensis) Hasil Tangkapan Trammel Net di Cilacap. Skripsi Sarjana Pada FPIK IPB Bogor : Tidak diterbitkan. 
Motoh, H. (1981). Studies on the fisheries biology of the giant tiger prawn, Penaeus monodon, in The Philippines. SEAFDEC Tech. Pap. (7). 128.

Naamin, N. (1984). Dinamika populasi udang jerbung (Penaeus merguiensis de Maan) di perairan Arafura dan alternatif pengelolaannya. Disertasi. Doktor pada Fakultas Pasca Sarjana. Institut Pertanian Bogor. Bogor. 381 p.

Niamaimandi, N., Arshad, A.B., Daud, S.K, Saed, R.C. \& Kiabi, B. (2007). Population dynamics of green tiger prawn, Penaeus semisulcatus (de Haan) in Bushehr coastal waters, Persian Gulf. Fisheries Research, 86, 105-112.

Pauly, D. (1983). Some simple methods for the assessment of tropical fish stocks. FAO Fisheries Technical Paper (254). 52p.

Pauly, D., Ingles, J. \& Neal, R. (1984). Application to shrimp stocks of objective methods for the estimation of growth, mortality and recruitment-related parameters from legth-frequency date (ELEFAN I and II). Penaeid shrimps-Their biology and management. Fishing News Books Ltd. 308 P.
Sparre, P. \& Venema, S.C. (1992). Introduction to tropical fish stock assessment. Part 1. Manual, FAO Fisheries Technical Paper No. 306.Rev.1. Rome, FAO, 376P.

Suman, A \& Boer, M. (2005). Ukuran pertama kali matang kelamin, musim pemijahan dan parameter pertumbuhan udang dogol (Metapenaeus ensis de Haan) di Perairan Cilacap dan Sekitarnya. Jurnal Penelitian Perikanan Indonesia, 11 (2), 69-74. doi: 10.15578/jppi.11.2.2005.6974 .

Suman, A \& Umar, C. (2010). Dinamika populasi udang putih (Penaeus merguiensis de Mann) di perairan Kotabaru, Kalimantan Selatan. Jurnal Penelitian Perikanan Indonesia, 16 (1), 29-33. doi: 10.15578/ jppi.16.1.2010.29-33.

Suman, A., Prisantoso, B. I. \& Kembaren, D.D. (2017). Parameter populasi udang dogol (Metapenaeus ensis) dan udang windu (Penaeus monodon) di Laut Arafura. BAWAL, 9 (1), 57-62. doi: 10.15578/bawal.9.1.2017.5762.

Udupa, K.S. (1986). Statistical Method of Estimating the Size at First Maturity in Fishes. Fishbyte. 4 (2), 8-10. ICLARM. Metro Manila. 
Lampiran 1. Sebaran frekuensi panjang karapas udang dogol jantan di perairan Selat Bangka, 2014.

Appendix 1. Distribution of carapace length frequency for male greasyback shrimp in Bangka Strait, 2014.

\begin{tabular}{cccccccccccc}
\hline $\mathbf{C L}$ & & & \multicolumn{1}{c}{ (n) jantan } & & & \\
& Feb & Mar & apr & mei & juni & juli & agust & sept & okt & nov & Total \\
\hline 18 & & & 1 & 3 & & & & & & & 4 \\
20 & 3 & & 1 & 12 & 1 & & & & 1 & 1 & 19 \\
22 & 6 & & 1 & 16 & 2 & & & & 1 & 5 & 31 \\
24 & 5 & & 11 & 10 & 8 & 4 & 1 & 2 & 3 & 4 & 48 \\
26 & 28 & 6 & 21 & 17 & 21 & 13 & 1 & 5 & 16 & 6 & 134 \\
28 & 30 & 6 & 15 & 11 & 19 & 5 & 4 & 6 & 7 & 9 & 112 \\
30 & 4 & 3 & 9 & 4 & 11 & 8 & 3 & 3 & 5 & 5 & 55 \\
32 & 2 & 3 & 3 & 2 & 8 & 4 & 5 & 7 & 3 & 6 & 43 \\
34 & 1 & & 5 & 1 & 3 & 2 & 4 & & 1 & 1 & 18 \\
36 & & & 6 & 1 & 3 & 3 & 5 & 3 & 3 & 4 & 28 \\
38 & & & 1 & & & & 2 & 2 & 1 & 3 & 9 \\
40 & & & & & 1 & & 2 & 2 & 1 & & 6 \\
42 & & & 1 & & & 1 & 4 & 2 & 1 & 3 & 12 \\
44 & & & & & & 1 & 1 & 1 & 1 & 1 & 5 \\
\hline Total & 79 & 18 & 75 & 77 & 77 & 41 & 32 & 33 & 44 & 48 & 524 \\
\hline
\end{tabular}

Lampiran 2. Sebaran frekuensi panjang karapas udang dogol betina di perairan Selat Bangka, 2014.

Appendix 2. Distribution of carapace length frequency for female greasyback shrimp in Bangka strait, 2014.

\begin{tabular}{|c|c|c|c|c|c|c|c|c|c|c|c|}
\hline \multirow{2}{*}{ CL } & \multicolumn{11}{|c|}{ (n) betina } \\
\hline & Feb & Mar & apr & mei & jun & jul & agu & sep & okt & nov & Total \\
\hline 18 & 1 & & & 3 & & & & & & & 4 \\
\hline 20 & & 1 & 2 & 10 & 4 & & & & 1 & 1 & 19 \\
\hline 22 & 4 & & 2 & 9 & 3 & 1 & 3 & 2 & 1 & 8 & 33 \\
\hline 24 & 4 & 1 & 2 & 11 & 5 & 3 & 7 & 6 & 5 & 7 & 51 \\
\hline 26 & 4 & 3 & 16 & 24 & 10 & 10 & 7 & 9 & 13 & 10 & 106 \\
\hline 28 & 3 & 5 & 20 & 16 & 28 & 20 & 19 & 14 & 16 & 21 & 162 \\
\hline 30 & 21 & 4 & 19 & 11 & 29 & 31 & 21 & 25 & 26 & 20 & 207 \\
\hline 32 & 20 & 6 & 22 & 5 & 14 & 33 & 24 & 34 & 30 & 16 & 204 \\
\hline 34 & 16 & 5 & 15 & 5 & 16 & 17 & 25 & 18 & 14 & 14 & 145 \\
\hline 36 & 11 & 2 & 8 & 4 & 8 & 26 & 15 & 20 & 19 & 16 & 129 \\
\hline 38 & 15 & 1 & 9 & 3 & 3 & 9 & 10 & 7 & 7 & 14 & 78 \\
\hline 40 & 5 & & 5 & & 1 & 2 & 10 & 9 & 7 & 4 & 43 \\
\hline 42 & 3 & 1 & 2 & 1 & 2 & 4 & 11 & 7 & 3 & 5 & 39 \\
\hline 44 & & & 2 & & & & 3 & 3 & 2 & 6 & 16 \\
\hline 46 & & & 1 & & & & 5 & 5 & 5 & 1 & 17 \\
\hline 48 & & & & & & & 1 & 1 & 1 & 3 & 6 \\
\hline Total & 107 & 29 & 125 & 102 & 123 & 156 & 161 & 160 & 150 & 146 & 1259 \\
\hline
\end{tabular}

